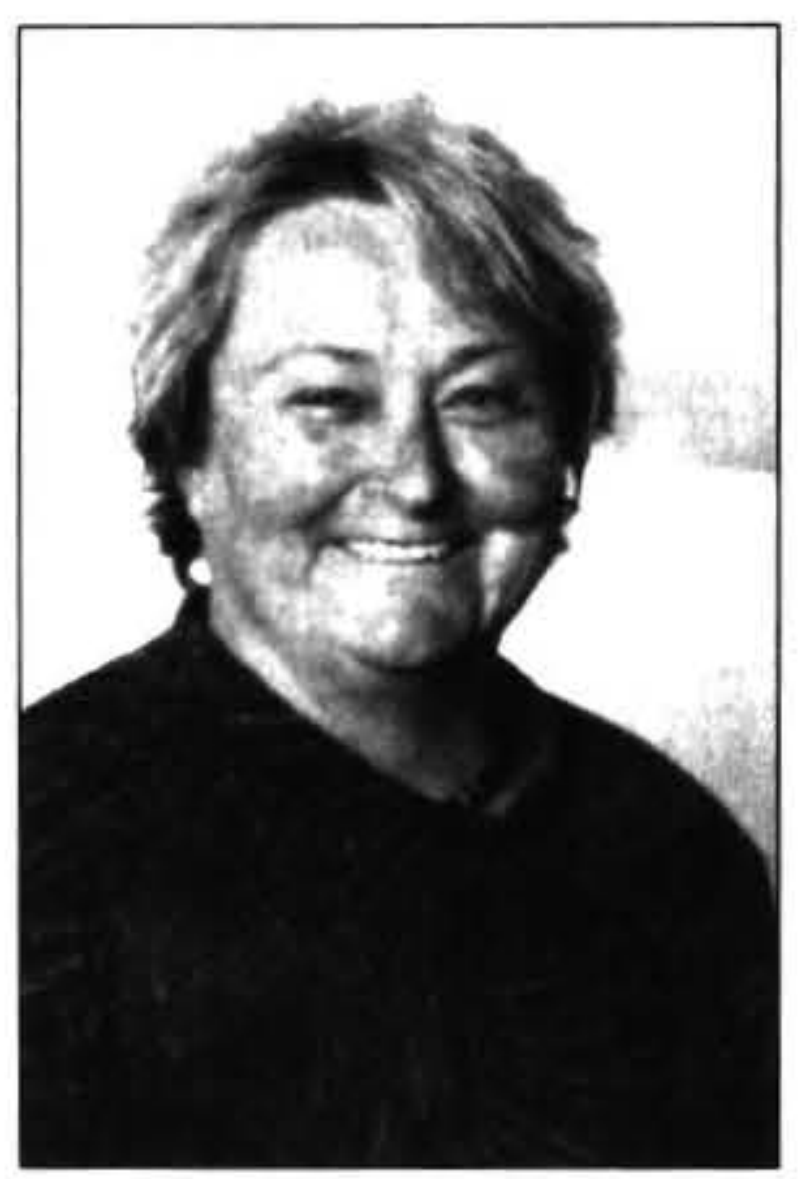

\title{
PROFESSIONAL SOCIALISATION INTO \\ PHYSIOTHERAPY: THE \\ WORKPLACE REALITIES
}

\author{
Maggie Roe-Shaw \\ Workplace Strategy and Capability. \\ Department of Labour. Wellington
}

\begin{abstract}
This paper illuminates the professional socialisation process in a variety of physiotherapy workplaces through engagement with a range of facilities and participants (including new graduates, physiotherapy managers and experienced physiotherapists). It explores being and hecoming a physiotherapist, and gives recognition to the importance of the workplace in the professional socialisation process. It reports positive workplace experiences for recent graduates, and identifies links between these experiences, professional career structures, and the attrition rate firm the profession. Just how well prepared are physiotherapists for the realities of the workplace? While this paper includes a theoretical model of professional socialisation. the focus is on the narrative model, which is the lived experience of physiotherapists in the context of practice in the constantly changing healthcare workplace through glohalisation and economic rationalisation.
\end{abstract}

\section{Introduction}

The focus of this paper is the challenging issue of professional socialisation into physiotherapy in New Zealand, as it is experienced by recent graduates'. Professional practice in the twenty-first century has seen the establishment of a "professional society" (Perkin. 1989), where an increasing number of occupations consider themselves to be members of a profession. Historically, professions have been granted status. autonomy, power and exclusivity, on the understanding they work for the good of society (Watson. 1992). Physiotherapy as practised in New Zealand is largely derived from the British model of physiotherapy education and practice, which emerged in the $1880^{\circ} \mathrm{s}$ in England (Barclay, 1994). From its beginnings as an emerging profession, physiotherapy took medicine as its professional model and developed a professional society with a standardised. supervised training program with written codes of practice (Morris, 2002).

In physiotherapy today, enormous changes are occurring within the profession to keep pace with the impacts on health care of globalisation effects such as the escalating advances in information technology. These changes in physiotherapy practice and professionalisation include expanding professional accountability, the focus on evidence-based practice by physiotherapists, and consumers expectations of best practice. Physiotherapy undergraduate programs aim to ensure high quality care for patients, and remain based on high academic achievement (Ohman el al. 1999; Morris, 2002). Recently there has been a demand that physiotherapy education reflects there are many generic skills needed to practice physiotherapy, in addition to competence (Higgs and Hunt, 1999; Richardson 1999). These generic skills include the ability to be situationally responsive to a wide range of patient encounters, flexibility, and effective listening and communication skills (Rothstein, 2000; Higgs and Hunt, 1999). So just what is the experience of being and becoming a physiotherapist really like? How well does the academic program prepare health professionals for the realities of the workplace?

Literature exploring the professional socialisation process is more prolific in professions other than physiotherapy and is most heavily weighted towards nursing and medicine. There are few accounts of research that purposefully investigate the content, process and outcomes of professional socialisation in the workplace. What socialisation occurs in the workplace? Is there a formal process of professional socialisation? What does it intend to achieve? How well does it succeed? Is it of benefit to the employer or employee? Is it of benefit to the profession? What benefit does it add to the individual graduate and the profession?

\section{Professional Socialisation}

Professional socialisation refers to the way in which the physiotherapy profession encourages and facilitates recent graduates into the workplace. This is not a single event, but encompasses the on-going development of individuals through interactions with their workplace environment and environmental situations. Thus the process of professional socialisation is not isolated to the workplace; it commences before the student enters the physiotherapy program, ${ }^{2}$ through contact with physiotherapists, continues through the undergraduate 
program, and in the clinical setting. Socialisation in the workplace can occur through orientation, induction, mentoring, supervision and continuing professional development (Cant and Higgs, 1999).

\section{Research Methods}

This study adopted a qualitative research design within the interpretive paradigm, utilising the research approach phenomenology of practice as informed by the work of van Manen (2002). The use of an interpretive approach allowed orientation to exploration, discovery and inductive logic, which allowed the study of influential workplace experiences and workplace factors to occur with contextual integrity. This paradigm enabled workplace factors that are important in the process of professional socialisation into physiotherapy to be described and interpreted. My major research question was what is it like to be a recently graduated physiotherapist in the workplace in New Zealand? In line with the research questions and approach, phenomenology of practice, data collection methods were focus groups, critical incident analysis, ${ }^{3}$ socialisation maps, ${ }^{4}$ and in-depth interviews. There were three participant groups in this study:

- Recently graduated physiotherapists employed in a variety of health care facilities including acute care, primary care, community care, private practice and rehabilitation in rural and urban New Zealand $(n=25)$. Selection of participants in this group involved purposive, maximum variation sampling (Miles and Huberman, 1994: Patton, 1990) to reflect the diversity of employment locations, employment types and employment variations of recently graduated physiotherapists.

- Physiotherapists with between 5-10 years experience who were employed in a variety of healthcare facilities in rural and urban New Zealand $(n=10)$. Selection of participants in this group was based on convenience and maximum variation sampling (Kuzel, 1992; Patton, 1990) to obtain a group of physiotherapists who were able to provide detailed and in-depth retrospective information about their physiotherapy workplace experiences (Rice and Ezzy, 1999). The participants in this group had all worked in several employment locations in New Zealand and overseas, and in a wide range of hospitals in New Zealand.

- Physiotherapy managers from all District Health Boards in New Zealand $(n=21)$. Selection of these participants was also based on purposive, maximum variation sampling (qua Patton, 1990).

\section{Development of Models of Professional Socialisation}

In phenomenological research, theory does not emerge from the data until immersion in the data (textual labour), familiarity with the data (grasping essential meaning), narrative organisation (anecdotal narrative) and active engagement with the data (identifying and experiencing themes) have occurred. From this study, two models were developed. The first, a theoretical model of professional socialisation, examined professional socialisation as a phenomenon, and is based on issues and themes emerging from the literature and the data. This model is highly specific to healthcare professionals in New Zealand. The second model, a narrative model of professional socialisation, portrays the actual experiences of physiotherapists through the depth and richness of the data collected from all participants.

The purpose and process of professional socialisation can be explored through the goals of acculturation, ${ }^{5}$ and in the theoretical model, two sets of themes were identified. The first set of themes relate to the experience of professional socialisation. The experiences of professional socialisation identified in the data include the dynamic workplace interactions of seeking, searching, coping and developing. These were identified as experience themes, and are shown in Table 1.

Table 1: Experience themes in theoretical model.

\begin{tabular}{|c|c|}
\hline ET1 & $\begin{array}{l}\text { Seeking a sense of professional direction } \\
\text { and identity }\end{array}$ \\
\hline ET2 & $\begin{array}{l}\text { Searching for professionalism in the } \\
\text { profession }\end{array}$ \\
\hline ET3 & le dissonance \\
\hline ET4 & $\begin{array}{l}\text { Developing the capability to address } \\
\text { various workplace roles and functions }\end{array}$ \\
\hline ET5 & $\begin{array}{l}\text { Coping with different practice models } \\
\text { within and beyond physiotherapy }\end{array}$ \\
\hline ET6 & Seekir \\
\hline
\end{tabular}

ET1: Seeking a sense of professional direction and identity for the recent graduate participants saw a common theme of 'not knowing' about the nature and scope of physiotherapy, and 'only really knowing about musculoskeletal physiotherapy'. ' The more experienced physiotherapists considered that physiotherapy within the hospital system lacked specific identity. Often this related to relationships with nurses and doctors, for example "We are such a small profession there is so much misunderstanding about what our role is and what we can offer " Nick, P041).

ET2: Searching for professionalism in the workplace relates to environmental factors such as physical, cultural and social aspects of performance which can both enable and impede human performance in the workplace (Christiansen and Baum, 1991). The most common comment about the social environment in hospitals was about workplace conflict with both peers and other health professionals. For example;

"I think is confusing for the doctors and nurses to know what we actually can do. In the hospital there are the three main areas 
and no one knows what we do or whether we are any good at them anvway. Perhaps they have no idea of the extent of the training that we have had". (Georgina, P012).

ET3: Coping with role dissonance refers to the importance of being able to practice physiotherapy autonomously and independently, using their skills and knowledge in practice settings. The participants reported considerable confusion, lack of congruence, and what other professionals perceived their role to be. In part this is because they are protected from workplace realities as students, and had not been exposed to real life physiotherapy practice. For example;

"I had one placement in private practice where I just stood and watched. I was not allowed to touch any patients hut I did read a lot of hooks" (Tom, P048).

ET4: Developing the capability ${ }^{9}$ to address the various physiotherapy roles and functions in their practice is about a mixture of readiness, preparedness, skills, competencies and a positive sense of confidence in ones own ability to implement the role for which one has trained (Fraser and Greenhalgh, 2001). There was a real issue for the recent graduate group about the extent to which their capabilities matched the reality of their workplace as they had come to know it. For example;

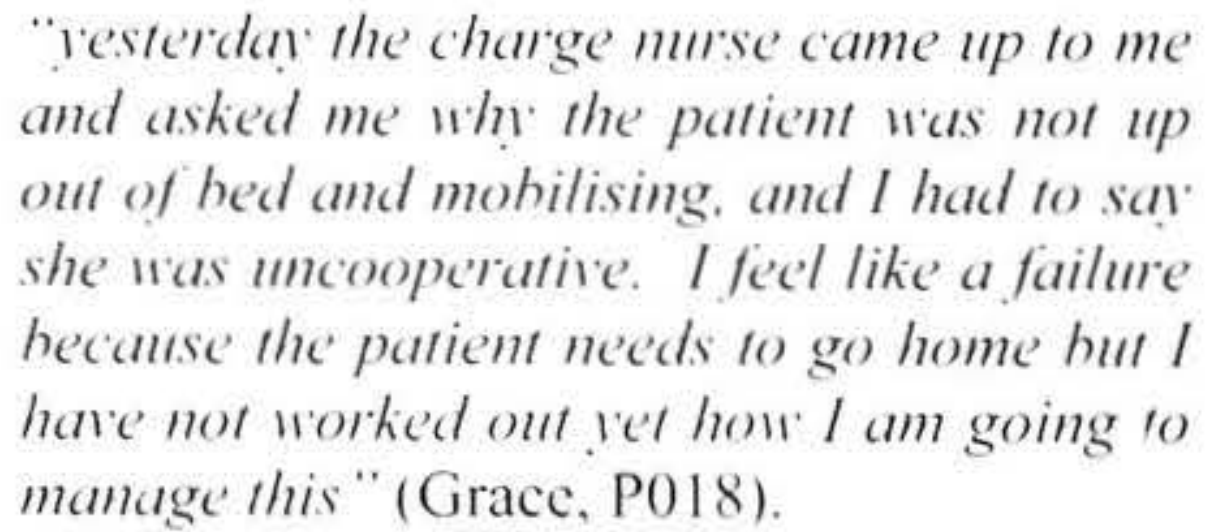

ET5: Coping with different practice models within and beyond physiotherapy was again a difficulty for the recent graduates. Physiotherapy has many different models of practice that address the different phenomena within the biophysical and socio-cultural spectrum. The type of undergraduate education, the role models and clinical experiences influence the models recent graduates choose to adopt. In physiotherapy broad practice models include medical model ${ }^{10}$, evidence-based practice, patient-centred care, and in some community settings, wellness models. The difficulty in coping with different practice models was often about outdated practice models where recent graduates referred to senior colleagues who had not kept up with current practice.

"The mumber of seniors who refuse to keep up to date with new ideas, techniques and literature and who rels on text books shocked me. They are not interested in the patient s wellheing. and they believe they know what works and what doesn't and that is nearly always electrotherap!" (Diane. P(9)
ET6: Seeking career and job satisfaction includes the motivation to remain in a job and includes the satisfaction with the workplace itself, a sense of achievement, a sense of recognition, a sense of responsibility and a sense of advancement (Herzberg, 1993). Job satisfaction can be explained through two dimensions of satisfaction: satisfiers and dissatisfiers, and be defined as work environment that develops employees to feel motivated, productive and fulfilled"l. In physiotherapy this is about having a successful patient encounter. For example;

"The most rewarding thing for me is when I
do something that really makes a
difference. When I know it is because of my
intervention they are able to get back to
sport then that is quite a rewarding
experience" (Hamish, P020).

\section{Context Themes in the Theoretical Model}

The second set of themes in the theoretical model related to the context factors identified in this study that contributed to shaping the socialisation reality for recent graduates. The contextual factors operate in the environment and frameworks of the workplace and the profession. Descriptions of the context themes are shown in Table 2.

Table 2: Context themes in the theoretical model.

\begin{tabular}{|l|l|}
\hline CT1 & $\begin{array}{l}\text { Undergraduate preparation for workplace } \\
\text { reality and professional role. }\end{array}$ \\
\hline CT2 & Mentoring and collegial support \\
\hline CT3 & Professional recognition of person and role \\
\hline CT4 & System support and resources. \\
\hline CT5 & $\begin{array}{l}\text { System rules, restrictions, norms and } \\
\text { expectations }\end{array}$ \\
\hline CT6 & Professional development opportunities \\
\hline CT7 & Career options \\
\hline CT8 & Financial issues \\
\hline
\end{tabular}

CT1: Undergraduate preparation for workplace reality and professional role varies between the two training schools ${ }^{12}$. However, all recent graduates were aware of the mis-match between what they were taught and the realities of the workplace.

CT2: Mentoring and collegial support has been described as having chemistry, serendipity and reciprocity, which is symbiotic by nature, and mutually beneficial (Sydenham, 1990). Descriptors of the factors that made other physiotherapists role models included;

"their enthusiasm and their passion for their patients" (Anne, P01), and "they were alway's so organised and knowledgeable and always positive about their patient encounters" (Darryl, P06). 
CT3: Professional recognition of person and role relates strongly to the theme of professional identity and career satisfaction, and in the recent graduate participants the lack of recognition in hospital settings was common. For example, "I think at the moment physiotherapy is quite tradition - based in this hospital because we are expected to go and do glorified nursing jobs like mobilising patients to the toilet" (Brenda, P02).

CT4: Support systems and resources have been shown to influence the commitment and skill of staff (Reilly, 1996). Where these expectations differ, for example where poor professional expectations and negative professional respect exists, workplace performance is affected (Cant and Higgs, 1999). For example, "I find it so hard because although I have a supervisor now she only graduated a year before me so I have no senior or experienced staff to reinforce what I am doing"(Anastasia, P021).

CT5: Systems rules, restrictions, norms and expectations are important in the context of workplace learning in improving performance for the organisation and improving learning for the benefit of the employee (Boud, 1998). The physiotherapy managers working for $\mathrm{DHBs}^{13}$ have very different roles within the system. For example, one manager although describing her role as powerful, had no influence over the number of physiotherapists or her budget for employment of physiotherapists. For example;

"I can take the profession anywhere I like because I am able to influence business planning and general managers. However the recruitment of physiotherapists is a line manager role so it is not my call" (Monty, P077).

CT6: Professional development opportunities in the workplace are quite limited for recent graduates, although there is an expectation for increased accountability for practice since the introduction of the Health Practitioners Competence Assurance Act (2003). Those in the public sector had to fight for funding for external course, for example;

\begin{abstract}
"there are no opportunities here for us for professional development. They just put notices on the notice board, and you can see what you might like to go to, but they are reluctant to pay for you to go " (Nancy, P019).
\end{abstract}

However, in the private sector things were more easily available, for example "they put a lot of emphasis on inservice-training every week to talk over technical issues of difficult patients" (Hamish, P020).

CT7: Career options is used in a vocational context to describe movement within a profession, and from one role to another, and the $21 \mathrm{DHBs}$ all have very different organisational structures which impact on the career choices. The attrition rate from the profession is enormous and there are very few career physiotherapists in the public sector. For example we have very young staff: most of our staff is under 35 and very few would be at the ten year mark" (Mary, P070).

CT8: Financial issues are a problem for physiotherapists in New Zealand where remuneration is poor compared to other professions. For example;

"physiotherapy is not paid as well as
nursing and it is certainly falling behind
teaching and policing. We are loosing staff
to these professions; in fact we have had
four leave this year already. They went to
teaching, law, accounting and the police. I
think they were fed up with the demands
made on them. We are the highest paying
DHB in the country but we still have
difficulty attracting and retaining staff"
(Monty, P073).

\section{Context Themes in the Narrative Model}

The purpose of the narrative model is to represent the range of contexts and experiences of the participants to illuminate then phenomenon of workplace reality and the professional socialisation of physiotherapists. It also illuminates the participants' lived experiences of workplace realities, their volitional ${ }^{14}$ thoughts and feelings along with factors that contribute to these experiences and potential actions to remediate professional socialisation. What emerged strongly from the data were eight context themes that contributed to situational reality in the workplace. These narrative context themes derived from the data and are shown in Table 3.

Table 3: Context themes in the narrative model.

NCT1: Limited undergraduate preparation for the reality of workplace

NCT2: Lack of mentoring an collegial support

NCT3: Lack of professional recognition of person and role

NCT4: Limited system support and resources

NCT5: Conflicting system rules, restrictions, norms and expectations

NCT6: Limited professional development opportunities

\section{NCT7: Restricted career options}

NCT8: Financial difficulties

NCT1: Limited undergraduate preparation for the reality of the workplace. The participants described a range of workplace realties, but most of them expressed frustration with their preparations and expectations that were generated in the undergraduate clinical program. For example; 
"It was very difficult to come out of University with all these ideas that the School of Physiotherapy told us how clinical practice would be. It was demoralising to find how little professional respect we have" (Alan, $\mathrm{P} 03$ ).

Another common theme was "I think the needs of the workplace should be identified in the training program" (Katie, P017). The skills that graduates need to work in acute care settings, emergency departments and intensive care units are not a curriculum requirement, and although some students may get to experience physiotherapy in acute care during their cardiopulmonary experiences, the majority do not. Yet they are expected to be on-call once they are qualified. For example.

\begin{abstract}
"I was called to intensive care the second night I was on-call and it was rough. I would not wish that experience on amione. I don't think it should happen. You don't see trainee interns, doctors or nurses being sent in there unsupervised but we are" (Alan, P03).
\end{abstract}

The lack of reality between their clinical education experiences and the workplace were also highlighted. For example. "my clinical educators would go and find me co-operative patients who were willing to have physiotherapy: and it has been a rude shock to find that in reality some people are rude. uncooperative and refuse to get out of bed (Grace, P018). The physiotherapy managers voiced concerns about the lack of preparation for the workplace, and two themes from the focus groups were a lack of competence to practice safely and an inahility to complete case notes. Another manager noted that:

\begin{abstract}
"I want gradtuates to have good basic competence and it is worrying to see them coming out without a hasic grasp of assessment. I found a recent graduate was telling all her patients to come back in a fortnight. She was seeing them and sending them anat without any treatment. It was aroidance hecause she didn't know how to treat them" (Michelle. P073).
\end{abstract}

NCT2: Lack of mentoring and collegial support. The participants reported a range of factors that related to the lack of mentoring and collegial support they received in their first workplace. Where mentors had made influences recent graduates was highlighted in their critical incident analysis of their positive and not so positive clinical experiences. Theses influences included motivation and enthusiasm such as "she was so motivated and enthusiastic about what she was doing, it challenged me ahout what I was doing and why" (Errol, P08). These influences also included respect and access such as "he was so approachable and at the same time knowledgeable and he gave me a glimpse of the way ahead for physio" (Andrew, P011). The lack of senior staff meant for many graduates there was no feedback or supervision and recurring themes were having to sink or swim and being thrown in at the deep end. The transition from full on supervision in clinical placements to being left unsupervised was also a challenge for some. For example;

"I guess when I was a student the treatment I gave a patient wasn't that important because I was only there for six weeks and my supervisor organised my day. What is hard now is that if I cannot make a difference I feel like I have let the patient down and I have nobody to fall back on or discuss things with on this rotation" (John, P013).

The participants working in private practice also had difficulties with feeling left on their own. For example;
"At the interview he promised when I started work I would get supervision and in-services, but once I started I was on my own. He was very focussed on running his business an appeared to have forgotten about helping people, and so instead of supervision I got his patients as well. Because he was so busy he would get the receptionist to put on hot-packs and do ultra-sound and just used machines ${ }^{15}$ because we had no time to assess and treat otherwise. In the end I left because I felt I was about as useful as the receptionist" (Bill, P04)

NCT3: Lack of professional recognition of person and role. The participants described a variety of factors that influenced professional recognition of themselves as physiotherapists. In particular, the feeling of disempowerment was a common theme across all workplace types, both the public and private sector. For example;

"the doctors have such an ill-defined understanding of how physios operate. They wait until something is chronic and then refer it to the practice. The whole point is that they should be referred at the acute stage" (Darryl, P06).

And in the public sector;

"I am treated as the mobility person. All I do is get people out of bed or get people up into the chair depending what the consultants and house surgeons tell you what they want done" (Diane, P09).

A large number of participants also feel their role was mis-understood by nurses. For example;

"the nurses page you and say come here now. The patient is desaturating ${ }^{16}$ and I would ask if they had changed position or suctioned them. just the normal nursing 
tasks in this situation but they would still order me to come" (Christine, P07).

The experienced physiotherapists, who had reached senior positions, still reflected a sense of being undervalued and not recognised for what they were able to offer the workplace.

NCT4: Limited support systems and resources. The participants described a variety of dimensions that influenced this including brief orientation programs, no support for on-call weekend work, and the lack of equipment available for patients. For example;

"things like walking frames and crutches are so difficult to access on the weekend. I am called in to get people up on crutches and when you have to hunt for crutches it is just a waste of time" (Brenda, P02).

The on call dilemmas also showed that most recent graduates had no belief in the efficacy of cardiopulmonary physiotherapy and were often called in because the medical staff did not know what to with the patient. For example,

"I do not think the hospital system helps at all when it comes to on-call. It gets me down and I am beating my head on a brick wall because it supposed to be an emergency service and when I get there it is end stage CORD ${ }^{17}$ and the doctor is standing there saving lets see what physiotherapy can do because there is nothing more that the medical profession can do. The most I can do is make them comfortable but that is not physiotherapy. and it certainly not an emergency." (Nancy, P019).

The fifth and sixth dimensions of this theme related to limited physical resources such as internet and libraries. For example,

"I think it really important to be able to go to the internet and look up articles on line or mavbe a condition you have not come across before. You have to have time to look things up and learn " (Errol, P08).

NCT5: Conflicting system rules, restrictions, norms and expectation dimensions were those of hierarchy and time and paper management. The hierarchy in management was highlighted by the experienced physiotherapists, for example;

"when I started work the person in charge of me was a physiotherapist, so they were on the side of the profession. Now I am structured under a department with a manager with a background of economics and that is fragmenting and nonsupportive" (Heather, P042).
A consistent theme arising from the data was the place the participants saw physiotherapy fitting into the hospital hierarchy was that they were the bottom of the pile, and least well recognised. For example, "I feel we have had different training from other disciplines, and therefore we are better equipped to make certain decisions and judgements about patients, but I don't function well in this hierarchy" (Diana, P09).

NCT6: Limited professional development opportunities were seen quite differently from those in the private and public sectors. Those employed in private practices were sent on extensive musculoskeletal courses by their employer(s) to up-skill them in techniques specific to their practice that was not taught by the Schools of Physiotherapy. However they did have a compulsory one hour in-service each week presented by another staff member:
"we have a weekly in-service that is compulsory in your lunch hour. You have to rush down to the basement with your lunch and ry and take in what one of your peers is saving about something. Sometimes it is useful and sometimes just regurgitation of a text book. My flatmate works in an office and they get an hour for lunch and do not have to rush to do professional development in their lunch hour. Yet we are expected to do that as well as manage our case-load" (Brenda, P02).

NCT7: Restricted career options were mentioned by all participants in part because of financial remuneration and in part because of a lack of career structure in the public sector. For example;

"I do not see how there is any more on physiotherapy in working a maximum of five years. I do not want to do it forever. I am just doing prescriptive physiotherapy. and I feel like a nurse aide. I do not want to go into private practice because you have to see too many patients a day to make money, so I only have the choice to stav in the hospital where the pay is so bad. It is probably the reason there is no incentive for me to stay and work as a physiotherapist. I want to have kids and stuff and I cannot afford to survive on what we get paid" (Grace, P018).

Leaving the profession was a common theme. For example:

"I am not sure where I am headed to be honest. I am sick of coming home and grumbling about work and I am actively looking the newspaper for other job opportunities, but since I have waited five years to be able to practice as a physiotherapist it seems a bit silly to let it go "(Errol, P08). 
And there was the theme of leave the country. For example;

"I want to go overseas to see the depth and breadth of physiotherapy that is missing here. I am excited by the fact there will be experience clinicians and there will be many people to learn from and work with" (Nick, 041).

NCT8: Financial difficulties were linked to both the low remuneration in the profession, and high cost of enrolling in the undergraduate program. Because there is a clinical component to the program, the cost is much higher than most other allied health profession. For example;

\begin{abstract}
"I perceive salan to be an estimation of worth. If I look at people in the hospital who get better salaries than physiotherapists (nurses and occupational therapists and social norkers and radiographers), then the sistem thinks thev are worth more than us in a way: So many phisiotherapists here are happy to do a technician's jog, and we get a technicians salary: I think ay gores with respect" (Alan. P03).
\end{abstract}

Many of their peers were working less highly skilled jobs and receiving more recompense. For example, "I struggle with pay scales when you consider the relative risk and the amoum of responsibility I have, compared to peers on much less stressful situations and get paid wice as much" "(Jane, P041)

\section{Experience Themes in the Narrative Model}

Table 4: Experience themes in the narrative model.

\author{
NET1: Experiencing a sense of direction and \\ identity
}

NET2: Experiencing a lack of professionalism in the workplace

NET3: Experiencing difficulty in coping with role dissonance

NET4: Experiencing difficulty in addressing the different roles and functions in physiotherapy practice

NET5: Experiencing difficulty in coping with different practice models within and beyond physiotherapy

NET6: Experiencing a lack of job and career satisfaction

What also emerged from the data were six themes of the experience of professional socialisation into the workplace. Each of these themes relate to how the participants were experiencing the workplace. These themes often overlapped, as multiple realities cannot be completely disengaged from one another. In the analysis of data I was looking for words, sentences and phrase that gave me a sense of the vocative, the vocatio ${ }^{18}$ of what the participants had experienced. These experience themes derived from the data and are shown in Table 4.

NET1: Experiencing a sense of direction and identity was described and experienced several ways by participants within their workplace(s). The link between these two is not as in seeking professionalism and recognition, but understanding what a physiotherapist is and what they can do. The participants are saying they recognise the healthcare system deficiencies, but know there are other places where they work and be more autonomous. Part of seeking a sense of direction was the knowledge that they needed to work in a workplace where they would not only grow and develop, but that they could use the talents and capabilities that they have. For example, "I understand now what people mean when they talk about life long learning because I know more now about what I don't know and still need to learn" (Anne, P01). The physiotherapy managers unanimously agreed that there was a loss of professional identity within physiotherapy in DHBs, as health care moves forward to a transdisciplinary model and organisational restructuring. For example;

"I don't think we develop professional identity very well. Our physiotherapists are working in different areas across the organisation because the organisational push is for multidisciplinary teaming. I think we have lost our identity with this change" (Megan, P082).

Seeking a sense of direction for their career was most common amongst those participants with between 3-5 years experience. For example;

\begin{abstract}
"the only sense of direction I have is to get into middle management. That would mean giving up physiotherapy and getting more money, but it would mean giving up working with people. That would be hard because I do love working with people and getting them better (Rose, P043).
\end{abstract}

NET2: Experiencing a lack of professionalism in the workplace refers to the expectations that recent graduates had of being able to move beyond safely supervised students, entering a profession and be playing a professional role ina professional arena. For example, "I thought the chance to work with other experienced phisios would be great because I assumed they had a passion for their job and would be right up there with the latest data and information on efficacy "(Alan, P03). They were looking for professionalism in the way they were treated in the workplace and I their senior colleagues. For example, "I was so motivated by my last supervisor hecause she was so inspiring with her positive attitude and realistic expectations for patients and her energy and enthusiasm about physiotherapy rubbed off on me" (Nancy, P019). On the other hand, having a negative role model also impacted. For example; 
"I was excited when I got this job. It was my first job and what took me totally by surprise was how low morale was and the huge amount of negativity in the workplace" (Diana, P09).

Seeking ethical behaviour models was a response from those working in private practice who felt that all their training and professionalism was being eroded by their workplace experiences. For example;

"I had to remove myself from my physio career to go and work for my boss because of her pressure on me to put through patient numbers. It was her business after all yet to see so many patients evervday when it not appropriate just for the dollars made me feel bad about being a physio" (Hamish, P020).

NET3: Experiencing difficulty in coping with role dissonance refers to the incongruity the recent graduates find between how their professional role will fit in the healthcare system, and their system expectations. Most of the recent graduates reflected this experience of role dissonance in terms of learning to cope and failing to cope by wither giving up or fighting the system. There was a general feeling of stress and anxiety about the lack of role clarity and compatibility. For example, "I did not expect to have my clinical judgements questioned by doctors and nurses" (Hamish, P020);

"I had no idea that physiotherapy in the surgical wards was just prescriptive treatments done like a technician. Worse. still was when I found out my senior colleagues agreed that there was no benefit or satisfaction for the patient, but they did not mind doing it (Diane, P09).

Coping with a heavy workload was a common dimension. For example;

\begin{abstract}
"There is just too much work. At the moment we have three physios on a ward with 64 beds and both the other physios were away. I had ten new patients and had to quickly learn to prioritise my caseload and see as many patients and I could, go without lunch and just manage it some how: But nobody died " (Christine, P07)
\end{abstract}

NET4: Experiencing difficulty in addressing the various functions and roles in their practice was a mixture of coping with the difficulty and complexity of the roles and tasks they were expected to perform in their workplace, and trying to juggle the high caseload these competing roles engendered. This theme reflects the participants' experiences in the workplace of engaging with both the clinical side of physiotherapy and the management structures within the different workplace settings. For example;
"I thought when I graduates I was on a level I knew everything and that I would know what to do with every patient. However, you hardly ever get patients that are the same, and all their problems are based on pain that is so subjective. It is hard to get my head around the fact I cannot be specific about what is causing their pain" (Anne, $\mathrm{P} 01$ ).

NET5: Experiencing difficulty in coping with the different practice models within and beyond physiotherapy refers to participants learning to deal with their learned practice models (idealistic), and the actual workplace models, which may include unsatisfactory or unprofessional practices. During undergraduate education, students are often caught up with the infrastructure of their education where they are taught knowledge and skills in isolation in isolation from clinical practice. This makes links between the academic papers and clinical practice difficult for them to grasp. For example, "I had no idea why we were learning about communication when it was mixed in with pathophysiology" (Bill, P05). One of the strong issues is that so much physiotherapy practice is not based on evidence. For example "all the techniques I had been taught to do made me feel uneasy and unprepared to treat patients when there was no evidence for what I was doing anvway" (Darryl, P06). And:
"In my experience with cardiopulmonary physiotherapy it seemed that it made no difference whether physiotherapy was done or not. It was very repetitive and did not appear to have someone so qualified to teach repeated deep breathing, and there is so little evidence in the literature to support it" (Andrew, P11).

NET6: Experiencing a lack of job and career satisfaction was a common trend in the data. The generalised dissatisfactions stemmed mostly from systems and organisational difficulties in the workplace that differed from their experiences in the undergraduate program. However, there were strong experiences of satisfaction expressed in their being able to help people, being able to make people better and improve patients' quality of life. For example;

"I staved on all night at ICU to treat her
until the Sunday physio started work. I was
so pleased to see that she pulled through
the pneumonia and that I had worked so
hard to achieve a result like this and that
what I did that night had made such a
difference. Iloved being part of the team at
ICU and seeing her improve when it didn't
seem likely" (Christine, P07)

\section{Conclusion}

The workplace is important. This paper reports the impact and influence that the workplace has on a specific health 
care group in New Zealand; physiotherapists. The major purpose of this study was to identify, describe and understand the nature of professional socialisation experiences and workplace factors that influence these. Little research in physiotherapy has explored the physiotherapy workplace as a way of illuminating and understanding the recurring problem of limited retention to, and attrition from the profession in New Zealand.

The theoretical model rethinks the nature of professional socialisation, emphasising lived experience and workplace realities. It looks inside the real world of practice as the context for post-graduate socialisation. There is potential to use the model to explore workplace realities and professional socialisation in other workplaces within and outside New Zealand. The narrative model illuminates the nature of, and factors influencing professional socialisation of physiotherapists in New Zealand. Two distinct themes emerged through data analysis; those of the socialisation experiences, and those of the workplace factors that contributed to those experiences.

\section{Future Research}

Little research in physiotherapy has previously explored the physiotherapy workplace as a way of illuminating and understanding the recurring problem of limited retention and attrition form the profession. The theoretical model rethinks the nature of professional socialisation, emphasising lived experiences and workplace realities. It looks inside the real world of practice for the context of professional socialisation, and there is potential to use this model to explore the workplace realities and professional socialisation in other disciplines within and beyond New Zealand.

My research also revealed a number of concerns about the structure of physiotherapy practice in New Zealand. The practice of physiotherapy in the public and private health sectors were reported to be very different by the participants. These differences and difficulties in the private sector, can in part, be explained by the dominance of ACC in New Zealand, and were reported to be stressful and difficult to manage by the participants. Further research is needed into the mental health and burnout of young health practitioners who are to consult with a new patient every ten to fifteen minutes in the private sector.

\section{Notes}

1 Graduates with between one and two experience in a variety if New Zealand workplaces (rural and urban District Health Boards, private practice. community centres and schools).

Most young people have some sports related injury requiring physiotherapy through $\mathrm{ACC}$.

A story that has an issue or dilemma to address and is a report of a particular positive or negative experience used to encourage reflection (Hewson, 1991).

Socialisation maps are concept maps used to portray social phenomena, i.e. the participants professional socialisation journeys (Gaines and Shaw, 1995).

Acculturation is an important and dynamic phenomenon which describes the influences and social and environmental changes on an individual's values, beliefs, behaviours and affect (Chun et al. 2003).

6 Professional identity consists of a set of values, ideas, attitudes, knowledge and skills which embodies the notion of what physiotherapists do in their workplace.

7 There are three main types of physiotherapy: musculoskeletal (usually done in a private practice and involves sports injuries, road trauma, or back pain), cardiopulmonary physiotherapy (usually done in a hospital for conditions like emphysema, bronchitis, asthma), and neurology (usually done in a rehabilitation centre or hospital for conditions such as strokes, Parkinsons and head injuries).

These are actual participants pseudonyms.

9 Capability is more than competence (Fraser \& Greenhalgh, 2001). It is defined as the extent to which individuals can adapt to change, generate new knowledge, and continue to improve their performance.

10 The doctor prescribes the treatment the physiotherapist will perform.

11 Syptak, Marsland and Ulmer, 1999.

12 Auckland University of Technology, School of Physiotherapy, and Otago University School of Physiotherapy.

13 The organisational structures have undergone significant organisational change in the last decade and now CEOs are appointed from a background of accounting, economics, law and management and few have any medical background.

14 Keilhofner (2003) describes the core of volitation as the thoughts and feelings about experiences which are believed to be shaped by previous experience, interpretation of that experience, and anticipation of further experiences.

15 Electrotherapy machines.

16 A serious lack of oxygen in the blood (usually less than $89 \%$ ). 
17 Chronic Obstructive Airways Disease. A slow progressive disease of the lungs usually caused by smoking.

18 The aim of vocation is to let things speak or be heard by bringing them into nearness through the vocative power of language

\section{References}

Barclay, J. (1994). In Good Hands: The History of the Chartered Society of Physiotherapy 1894-1994. Oxford: Butterworth Heinemann.

Boud, D., Freeland, J., Hawke, G., and McDonald, R (1998). More strategic, more critical, more evaluative: Perspectives on research into workplace learning and assessment. In Boud, D (ed.) Current Issues and New Agendas in Workplace Learning. Leabrook, S.A.: National Centre for Vocational Education Research Ltd.

Cant, R., and Higgs, J. (1999). Professional Socialisation. In Higgs, J. and Edwards, H. (eds) Educating Beginning Practitioners. Oxford: Butterworth-Heinemann.

Chun, K.M., Organista, P., and Marin, G. (2003). Acculturation. Washington DC: American Psychological Association.

Christiansen, C., and Baum, C. (1991). Occupational Therapy: Overcoming Human Performance Deficits. Thorofare, NJ: Slack.

Gaines, B., and Shaw, M. (1995). Collaboration Through Concept Maps. www.ksi.cpsc.ucalgary.ca/articles/CSCL95CM/ Accessed July 2006.

Herzberg, F., Mausner, B. and Snyderman, B. (1993). The Motivation to Work. Somerset, NJ: Transaction Publishers.

Hewson, M. (1991). Reflection in clinical teaching: an analysis of reflection-on-action and its implications for staffing residents Medical Teacher, 13, 227-244.

Higgs, J., and Hunt, A. (1999). Preparing for the workplace: Fostering generic attributes in allied health education programs. Journal of Allied Health, 28(4), 230-239.
Kuzel, A.J. (1992). Sampling in qualitative inquiry. In Crabteee, B, and Miller, W. (eds). Research Methods for Primary Care Series. Newbury Park: Sage.

Miles, B., and Huberman, A. (1994). Qualitative Data Analysis. Thousand Oaks: Sage.

Morris, J. (2002). Current issues of accountability in physiotherapy and higher education. Physiotherapy, 88(6), 354-363.

Ohman, A., and Hagg, K., and Dahlgren, L. (1999). Competent women and competing professions Advances in Physiotherapy, 1, 59-72.

Patton, M. (1990). Qualitative interviewing, In Patton, M. (ed) Qualitative Evaluation and Research Methods Newbury Park, California: Sage.

Perkin, H. (1989). The Rise of Professional Society. England Since 1800. London: Routledge.

Rice, P., and Ezzy, D. (1999). Qualitative Research Methods. South Melbourne: Oxford University Press.

Richardson, B. (1999). The Way Forward - How and Why? Advances in Physiotherapy, 1, 13-16.

Rothstein, J.M. (2000). Thirty years later. Physical Therapy, 80(1), 6-8.

Sydenham, G. (1990). Idealism to burnout: bridging the gap. Phvsiotherapy Canada, 42(5), 223-229.

van Manen, M. (2002). Writing in the Dark. Ontario: The Althouse Press.

Watson, D. (1992). The changing shape of professional education. In Bines, H., and Boud, D. (eds). Developing Professional Education. Buckingham: Open University Press.

\section{Author}

Maggie Roe-Shaw

Principal Advisor of Research and Evaluation

Workplace Strategy and Capability

Department of Labour

P.O. Box 3705

Wellington

Maggie.Roe-Shaw@dol.govt.nz 